\title{
Early Postnatal Care Practices for Mothers and Their Babies in Bangladesh: An Integrative Literature Review
}

\author{
Nusrat Jahan1, Md. Shahidul Islam²* \\ ${ }^{1}$ Casual Academic, School of Health, Faculty of Medicine and Health, University of New England, Armidale, NSW, Australia \\ ${ }^{2}$ School of Health, Faculty of Medicine and Health, University of New England, Armidale, NSW, Australia \\ Email: njahan3@une.edu.au, *mislam27@une.edu.au
}

How to cite this paper: Jahan, N., \& Islam, Md. S. (2022). Early Postnatal Care Practices for Mothers and Their Babies in Bangladesh: An Integrative Literature Review. Open Journal of Social Sciences, 10, 258-270. https://doi.org/10.4236/jss.2022.102018

Received: September 9, 2021

Accepted: February 20, 2022

Published: February 23, 2022

Copyright $\odot 2022$ by author(s) and Scientific Research Publishing Inc. This work is licensed under the Creative Commons Attribution International License (CC BY 4.0).

http://creativecommons.org/licenses/by/4.0/ (c) (i) Open Access

\begin{abstract}
This integrative review aimed to describe the experiences of early postnatal care practices for mothers and their babies in rural Bangladesh. This study was conducted using an integrative review method outlined by Coughlan, Cronin and Ryan. An integrative search in ProQuest, PubMed, CINAHL, Sociological Abstract, and Google Scholar was conducted. The key terms include safe motherhood, postnatal care, MDGs, newborn care, maternal mortality, TBAs, cultural practice in childbirth and Bangladesh. After screening of the full-text and guided by the relevance of the studies against the inclusion criteria, a total of 22 studies were selected for final review. The results reveal that women's behaviours and attitudes during the postnatal period are shaped by individual beliefs and views as well as by socio-cultural practices. It shows how indigenous knowledge and practices affected women's postnatal care practices for generations. From the results, it is clear that rural women in Bangladesh followed many cultural practices during childbirth and postnatal period. In rural Bangladesh, postnatal care behaviour is mostly imposed by traditional cultural practices. Therefore, it is important to understand women's cultural practices around childbirth, and in particular to understand their experiences during the postnatal period.
\end{abstract}

\section{Keywords}

Postnatal, Childbirth, Mothers, Babies, Bangladesh

\section{Introduction}

The postnatal period is the final stage of the childbirth experience where many 
cultural practices and traditions are deeply influenced the lives of women in this time (Shakya, 2006). Social processes and cultural beliefs and practices are interconnected with the biological and healthcare processes of childbirth and postnatal care, and culture plays a prominent role in affecting a mother's experience and shaping mothering behaviour time (Darmstadt et al., 2006; Edhborg et al., 2015).

Most mothers in Bangladesh do not receive postnatal care services from Skilled Birth Attendants (SBAs), either for themselves or their babies, despite the implementation of safe motherhood strategies and the implementation of the Millenium Development Goals (MDGs) (NIPORT, 2016; Sines et al., 2007). The Bangladesh Demographic and Health Survey 2014 states that around one-third of all mothers received postnatal care from SBAs or had access to quality healthcare services when difficulties arose (NIPORT, 2016). The reasons for the poor utilisation of postnatal care services in Bangladesh have been raised by a number of researchers. For example, Winch et al. (2005) have reported that there are many cultural, social and economic barriers that delay Bangladeshi women from seeking postnatal care services. Walton and Schbley (2013) have contended that traditional beliefs and practices are the major obstacle to improving postnatal care for women in Bangladesh. In Bangladesh, there is a paucity of literature that addresses cultural practices in early postnatal care practices for mother and babies. Therefore, this study aimed to describe the experiences of early postnatal care practices for mothers and their babies in Bangladesh.

\section{Methods}

This study was conducted using an integrative review method outlined by Coughlan, Cronin and Ryan (2013). This method has been adopted widely within health and nursing research to facilitate the synthesis of the existing empirical literature to improve the quality of healthcare (Freire et al., 2014). The advantage of an integrative literature review is that it can examine the findings of studies that employ diverse research methodologies (Whittemore \& Knafl, 2005). For example, the integrative method provides a rigorous analysis of the existing literature whose sources are not limited to empirical studies, but that draw on material from diverse sources, such as theoretical and conceptual literature (Coughlan et al., 2013). Thus, an integrative review has allowed this review to include both quantitative and qualitative studies, to provide a more comprehensive understanding of postnatal care practices, and thus to build new knowledge informing practice, policy and research (Coughlan et al., 2013).

\subsection{Inclusion and Exclusion Criteria}

In this research, the inclusion and exclusion criteria have been divided into two sections, according to the two sets of literature. One was epidemiological and the other was women's experiences of cultural practices. The inclusion criteria for the epidemiological scenario were: only reports emphasizing the status of ma- 
ternal and newborn health; the effects of safe motherhood strategies in relation to the achievement of the MDGs, and English-language sources. The inclusion criteria of cultural practices during childbirth and the postnatal period were: cultural perspectives related to childbirth and postnatal care practices in Bangladesh, literature published between September 2000 (MDGs launched 6 to 8 September on this year) and December 2017, English-language sources. The exclusion criteria were: literature in languages other than English, studies conducted outside Bangladesh, literature published before the MDGs targets were set in 2000 .

\subsection{Search Terms and Strategy}

An integrative literature search was conducted using a number of databases, including ProQuest, PubMed, CINAHL, Sociological Abstract, and Google Scholar. The search strategy had been based on searching for several primary key terms relevant to the research question, aims and objectives, including safe motherhood, postnatal care, MDGs, newborn care, maternal mortality, TBAs, cultural practice in childbirth and Bangladesh.

\subsection{Search Results}

A total of 856 journal articles, relevant reports and studies were identified from the database search as potentially useful for this research. After screening the titles, abstracts, duplication and studies not written in English, a total of 142 articles were selected for the eligibility of this literature review. Studies were further rejected $(n=47)$ if they were not available in full-text or if the studies were published before 2000 as the MDGs launched on this year. Lastly, following the screening of the full-text and guided by the relevance of the studies against the inclusion criteria, a total of 27 studies were selected for final review. Among these 27 studies, a total of five reports were used for the epidemiological section. These reports highlighted the major changes and progress that took place in Bangladesh's epidemiological scenario. Importantly, these reports did not consider cultural issues and practices that affect women's behaviour and early postnatal care practices. Therefore, excluding the studies that were used in epidemiological section, a total of 22 articles were selected for this review of cultural practices of Bangladesh (Figure 1).

\subsection{Quality Assessment}

In this research, we used the Australian National Health and Medical Research Council's recommended framework for assessing the quality of papers included in the review (National Health and Medical Research Council [NHMRC], 2009). Table 1 presents the grading criteria used to assess the level of evidence of each study, in line with NHMRC guidelines (Table 1). Additionally, we developed a summary table of the reviewed studies (Table 2). The components of the summary table included the author's name, title, year, study locations, methods, sample size, key concerns and key findings. 
Table 1. Levels of evidence's criteria.

Screening intervention

A systematic or integrative literature review of level II studies

A randomised controlled trial

A pseudo-randomised controlled trial (i.e., alternate allocation or some other method)

A comparative study with concurrent controls:

- Non-randomised, experimental trial - Cohort study - Case-control study

A comparative study without concurrent controls:

- Historical control study

- Two or more single-arm study

\section{Diagnostic accuracy}

A systematic or integrative literature review of level II studies

Valid reference standard, among consecutive persons with a defined clinical presentation

A study of test accuracy with: an independent, blinded comparison with a valid reference standard, among non-consecutive persons with a defined clinical presentation

A comparison with reference standard that does not meet the criteria required for Level II and III-1 evidence

Diagnostic case-control study

Case series Study of diagnostic yield (no reference standard)

IV

Table 2. Summary of the included studies.

\begin{tabular}{|c|c|c|c|c|}
\hline Reference details & $\begin{array}{c}\text { Method/Sample size/ } \\
\text { How recruited/ } \\
\text { Study area }\end{array}$ & Objectives & Findings/Results & $\begin{array}{c}\text { Evidence } \\
\text { level }\end{array}$ \\
\hline $\begin{array}{l}\text { Afsana, K. \& Rashid, S. F. (2001). } \\
\text { The challenges of meeting rural } \\
\text { Bangladeshi women's needs } \\
\text { in delivery care. }\end{array}$ & A qualitative approach & $\begin{array}{l}\text { To determine } \\
\text { how to improve } \\
\text { existing delivery } \\
\text { care services }\end{array}$ & $\begin{array}{l}\text { Most women who attended } \\
\text { the BHC because of } \\
\text { complications received } \\
\text { poor-quality care. }\end{array}$ & III-3 \\
\hline $\begin{array}{l}\text { Afsana, K. \& Rashid, S. F. (2009). } \\
\text { Constructions of birth in } \\
\text { Bangladesh. Springer Science } \\
\text { and Business Media }\end{array}$ & Ethnographic method & $\begin{array}{l}\text { To understand } \\
\text { constructions of } \\
\text { birth in } \\
\text { Bangladesh. }\end{array}$ & $\begin{array}{l}\text { The result shows that } \\
\text { childbirth is constructed in } \\
\text { discursive practices that affect } \\
\text { women's use of birth care. }\end{array}$ & III-3 \\
\hline $\begin{array}{l}\text { Andrews, J. Y. \& Dalal, K. (2011). } \\
\text { Umbilical cord-cutting } \\
\text { practices and place of delivery } \\
\text { in Bangladesh. }\end{array}$ & A cross-sectional survey & $\begin{array}{l}\text { To investigate } \\
\text { umbilical } \\
\text { cord-cutting } \\
\text { practices in } \\
\text { Bangladesh. }\end{array}$ & $\begin{array}{l}\text { The findings highlight the } \\
\text { importance of a clean } \\
\text { delivery kit, especially for } \\
\text { home deliveries. }\end{array}$ & III-3 \\
\hline $\begin{array}{l}\text { Ara, S., Islam, M. M., } \\
\text { Kamruzzaman, M., Elahi, M. T., } \\
\text { Rahman, S.S., \& Hossain, M. S. } \\
\text { (2013). Assessment of social, } \\
\text { economic and medical } \\
\text { determinant of safe motherhood } \\
\text { in Dhaka City: A cross-sectional } \\
\text { study. }\end{array}$ & A cross-sectional study & $\begin{array}{l}\text { To investigate } \\
\text { determinant of } \\
\text { safe motherhood. }\end{array}$ & $\begin{array}{l}\text { The result suggests that } \\
\text { socio-economic status is } \\
\text { critical in safe motherhood. }\end{array}$ & III-3 \\
\hline
\end{tabular}




\section{Continued}

Blum, L.S., Sharmin, T., \&

Ronsmans, C. (2006). Attending home vs. clinic-based deliveries: perspectives of SBAs in Matlab, Bangladesh

Chowdhury, A. M. R., Mahbub, A., \& Chowdhury, A. S. (2003). Skilled attendance at delivery in Bangladesh: An ethnographic study.

Choudhury, N., \& Ahmed, S. M. (2011). Maternal care practices among the ultra-poor households in rural Bangladesh: A qualitative exploratory study.

Choudhury, N., Moran, A. C., Alam, M. A., Ahsan, K. Z., Rashid, S. F., \& Streatfield, P. K. (2012). Beliefs and practices during pregnancy and childbirth in urban slums of Dhaka, Bangladesh.

Darmstadt, G. L., Syed, U., Patel, Z., \& Kabir, N. (2006). Review of domiciliary newborn care practices in Bangladesh.

Edhborg, M., Nasreen, H. E., \& Kabir, Z. N. (2015). I can't stop worrying about everything: Experiences of rural Bangladeshi women during the first postpartum months.

Haider, R., Rasheed, S., Sanghvi, T. G., Hassan, N., Pachon, H., Islam, S., \& Jalal, C. S. B. (2010). Breastfeeding in infancy: Identifying the program-relevant issues in Bangladesh.

Islam, M. T., Islam, N., Yoshimura, Y., Nisha, M. K., \& Yasmin, N. (2015). Newborn care practices in rural Bangladesh.
To identify the

Qualitative method experiences of SBAs in rural Bangladesh.

To examine the experiences of SBAs in Bangladesh.

\section{To explore} maternal care practices among ultra-poor households in rural Bangladesh.

To describe maternal beliefs and practices.

To improve neonatal outcomes for the implementation of interventions in Bangladesh.

To describe the experiences rural mothers during the first postpartum period in Bangladesh.

To identify issues to improve breastfeeding in infancy.

To describe the newborn care practices in rural Bangladesh.

Quantitative method
The result suggests that SBAs experienced a number of obstacles which include transportation, adequate equipment, lack of training.

The result suggests that women in Bangladesh prefer home delivery for numerous reasons which include less expensive, privacy, easiness, and travel.

The result suggests that cultural beliefs have a strong effect on maternal care practices among poor women in rural Bangladesh.

The result suggests that cultural beliefs have a strong impact on maternal beliefs and practices during pregnancy and childbirth in slum area of Bangladesh.

Cultural beliefs and practices are heavily prevalent in newborn care in Bangladesh.

The result suggests that rural Bangladeshi women experienced economic difficulties and health problems during the first postpartum period in Bangladesh.

common practices include early bathing, delayed initiation of breastfeeding, and unclean cord care. 


\section{Continued}

Khan, M. I., \& Islam, K. (2006).

Home delivery practices in

rural Bangladesh: A case of

passive violence to the women.

Moran A. C., Choudhury, N.,

Khan, N. U. Z., Karar, Z. A.,

Wahed, T., Rashid, S. F.

\& Alam, M. A. (2009).

Newborn care practices among

slum dwellers in Dhaka,

Bangladesh: A quantitative

and qualitative exploratory study.

Parkhurst, J., Rahman, S. A., \&

Ssengooba, F. (2006). Overcoming

access barriers for facility-based

delivery in low-income settings:

Insights from Bangladesh and

Uganda.

Rahman, A., Moran, A., Pervin,

J., Rahman, A., Rahman,

M. Yeasmin, S., \& Koblinsky,

M. (2011).

Effectiveness of an integrated approach to reduce perinatal mortality: Recent experiences from Matlab, Bangladesh.

Sarker, B.K., Rahman, M.,

Rahman, T., Hossain, J.,

Reichenbach, L., \& Mitra,

D. K. (2016). Reasons for

preference of home delivery

with TBAs in rural Bangladesh:

A qualitative exploration.

Sultana, A. (2010). Patriarchy and women's subordination:

A theoretical analysis.

Sundaram, M. E., Ali, H., Mehra,

S., Shamim, A. A., Ullah, B.,

Rashid, M., \& Labrique, A. (2016).

Early newborn ritual foods

correlate with delayed

controlled trial
A randomised

To examine home delivery care practices in rural Bangladesh.

Mixed methods

Qualitative methods

Quantitative method

Qualitative method

Literature review impact of patriarchy in Bangladesh.

To examine the factors associated with delayed breastfeeding in rural Bangladesh.

To examine access barriers for
The result suggests that home delivery by untrained women is very common in rural Bangladesh.

The results show that the majority of babies were bathed immediate after birth.

Exclusive breastfeeding was not common; the majority of women gave honey to their newborn babies.

The result suggests that social networks helped to overcome cost and transport barriers in III-3 both counties.

III-3 approach helped to reduce perinatal mortality rural Bangladesh.

The factors include traditional beliefs, cultural views, religious beliefs, beliefs in TBA, lack of transport, and lack of knowledge about maternal health services.

The result suggests that women are influenced by patriarchy through various ways which include low wages, violence, son's preference, education, household work and dowry.

The result shows that feeding other supplementary foods delayed initiation of breastfeeding in rural Bangladesh.

in rural Bangladesh. 


\section{Continued}

Tarafder, T., \& Sultan, P. (2014).

Reproductive health beliefs and their consequences: A case study in rural indigenous women in

Bangladesh.

Tasnim, S., Rahman, A., \& Shahabuddin, A. K. M. (2010). Access to skilled care at home during pregnancy and childbirth: Dhaka Bangladesh

Varghese, R. (2007).

Monster-in-law? The effect of co-resident mother-in-law on the welfare of Bangladesh daughters-in-law.
To examine reproductive health beliefs and

Qualitative method their consequences in rural indigenous women in Bangladesh.

To examine maternal care
A quasi-experimental method

Quantitative method services through provision of Skilled Birth Attendants.

To identify the impact of co-resident mother-in-law on the welfare of daughters-in-law in Bangladesh.
The result shows that mythical beliefs and misconceptions influence rural indigenous women's health negatively.

The SBAs are not available at home during pregnancy and childbirth in Bangladesh.

The result shows that living with the mother-in-law with their daughters-in-law negatively them.
I-V

\section{Results}

The results of this integrative review have been summarised in this section. The main themes reported in the reviewed articles have been examined and compared below.

\subsection{Food Restrictions}

Food taboos are common in pregnancy and the postnatal period in Bangladesh (Darmstadt et al., 2006; Choudhury \& Ahmed, 2011, Ara et al., 2013; Sarker et al., 2016). These are affected by cultural beliefs and practices. Rural women generally believed that eating certain types of food during pregnancy and the postnatal period were harmful to both mothers and their babies (Darmstadt et al., 2006). During the postnatal period, especially the period of seclusion, ${ }^{1}$ different foods were restricted, thus depriving women of sufficient nutrition (Choudhury \& Ahmed, 2011; Darmstadt et al., 2006). Many foods were thought to be inappropriate during lactation (Choudhury \& Ahmed, 2011). Darmstadt et al. (2006) found that bananas with seeds, eggs and leafy vegetables were prohibited during the postnatal period. Beef and Hilsa fish were thought to dry up the milk of a lactating mother, and to possibly cause postpartum diarrhoea. Food restrictions deprive women from benefiting from these protein-rich foods, which are needed by pregnant and postpartum women (Edhborg et al., 2015), thus risking malnourishment.

${ }^{1}$ The seclusion period starts immediately after childbirth, when the mother and baby are kept indoors for anywhere between five and 40 days after childbirth (Choudhury \& Ahmed, 2011; Choudhoury et al., 2012; Darmstadt et al., 2006). Edhborg et al. (2015) found that very few women restrict themselves for 40 days; staying inside for 14 - 15 days after childbirth is more common. 


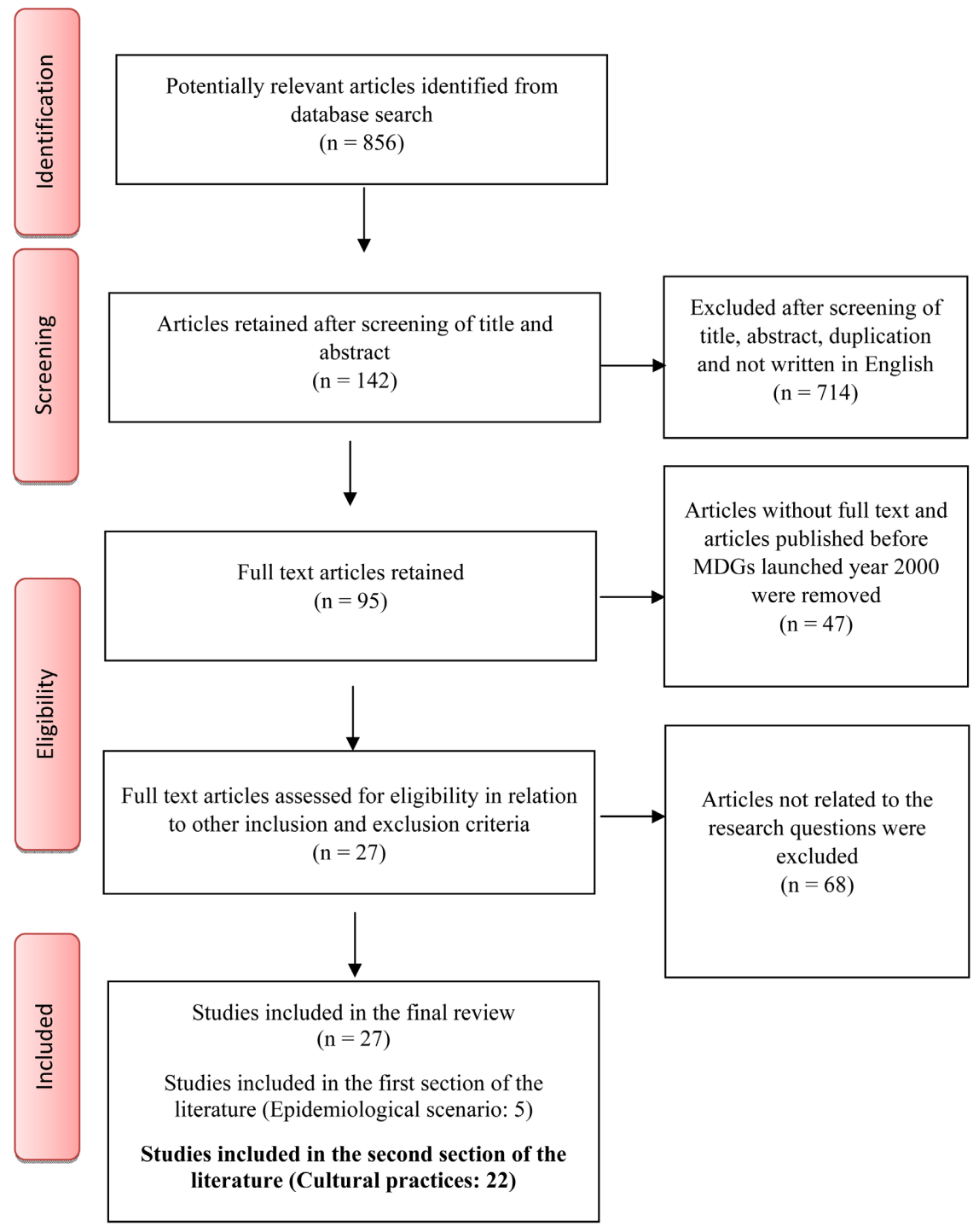

Figure 1. Flowchart of the literature selection process.

\subsection{Birth Preparedness}

Birth preparedness is vital for safe childbirth. Researchers identified some reasons for this, which were socially and culturally oriented (Darmstadt et al., 2006; Sultana, 2010). For example, Darmstadt et al. (2006) found that cultural beliefs regarding pregnancy and childbirth were different where childbirth was considered a natural event with many social and religious ramifications, rather than when it was thought of as a medical event. They found that in rural areas, many pregnant women had to work hard until the time of childbirth, and sometimes they gave birth at home or outside without preparation or an SBA. They also found unwillingness to prepare for childbirth. Most women did not even contact a dai in advance because they believed it would take more time to give birth if news of the impending birth spread among many people (Darmstadt et al., 2006). Choudhury and Ahmed (2011) identified poverty and traditional beliefs and rituals as a hindrance that delayed and sometimes stopped women from 
preparing for childbirth.

\subsection{Home Birthing}

The practice of childbirth at home is very common in Bangladesh (Khan \& Islam, 2006; Sarker et al., 2016). Research shows that rural women continue to give birth at home because it is a known environment, and because of the opportunity to have close ones nearby (Chowdhury et al., 2003; Sarker et al., 2016). Sixty-two percent of births occurred at home in 2014 (NIPORT, 2016), and a dai is the first choice for most rural people (Afsana \& Rashid, 2009; Sarker et al., 2016). Sometimes, women's mothers, relatives or neighbours help them during childbirth (Tasnim et al., 2010). Family members such as husbands, mothers-in-law and fathers-in-law give their opinions on where women will give birth to their babies, and they mostly prefer natural births at home, assisted by dais because of traditional views, religious beliefs, poor transportation, lack of awareness, fear of caesarean sections and lack of female doctors in healthcare facilities (Khan \& Islam, 2006; Parkhurst et al., 2006; Sarker et al., 2016; Varghese, 2007). Preference for male doctors is very low in rural areas.

\subsection{Seclusion and Evil Spirits}

The period after childbirth is considered a vulnerable time for new mothers and babies (Moran et al., 2009; Rahman et al., 2011). Rural people think that women are impure (napak) or polluted after birth, as a result of the birthing process (Blum et al., 2006). For this reason, they practice seclusion after childbirth, where they stay in a single room with their baby from fear of being attacked by evil spirits (Tarafder \& Sultan, 2014). Food cooked by a newly birthed woman is considered dangerous, and women are not even permitted to touch ingredients for meal preparation (Choudhury \& Ahmed, 2011). Because of this belief in impurity, some people felt encouraged to bathe the baby immediately, as they believed a baby's pollution could be removed by bathing (Moran et al., 2009).

\subsection{Newborn Care Practices}

Traditional practices outlined by researchers include those relating to cutting the umbilical cord and caring for the umbilical cord stump, bathing and breastfeeding (Darmstadt et al., 2006; NIPORT, 2016). Other traditional and cultural practices regarding newborn care can be observed, particularly in rural Bangladesh. For example, a harmful cord-cutting practice is followed, where instruments such as contaminated razor blades are used, because some women are still unaware of the importance of using hygienic equipment to prevent infections (Darmstadt et al., 2006; Islam et al., 2015; Moran et al., 2009). Applying heat massage (shek dewa) to the umbilical stump and surrounding area is almost universally practiced among women in rural Bangladesh, as it is considered a common part of home-based newborn care (Moran et al., 2009). The most common substances used on the cord are turmeric and boric powder (Andrews \& Dalal, 2011; Moran et al., 2009). 


\subsection{Breastfeeding}

Breastfeeding is recommended for improving babies' nutrition and development, and to help build immunity from common infections. Despite the nutritional value of breast milk, it has been observed that some mothers delay the practice of breastfeeding for up to three days after childbirth (Haider et al., 2010). While the practice of pre-lacteal feeding is not recommended because of the risk of gastrointestinal infection, about $27 \%$ of women give other liquids to their babies (NIPORT, 2016). Studies have shown that some cultural practices encourage pre-lacteal feeding, which goes against the WHO's recommendations for optimal breastfeeding (Sundaram et al., 2016). Additionally, there is a belief that colostrum is dirty milk because of its thick consistency, and it is thought to cause diarrhoea, abdominal pain and contain evil spirits (Darmstadt et al., 2006). As a result, rural women delay the early initiation of breast feeding, first putting honey or sugar water in their babies' mouths instead of breast milk (Haider et al., 2010; Moran et al., 2009). However, it has been found that the feeding of colostrum has increased, and $51 \%$ of mothers initiate breastfeeding within an hour of birth (NIPORT, 2016).

\section{Discussion}

Key results from this review suggest that women's behaviours and attitudes during the postnatal period are shaped by individual beliefs and views as well as by socio-cultural practices. In Bangladesh, several studies identified how indigenous knowledge and practices affected women's childbirth practices for generations (Choudhury \& Ahmed, 2011; Choudhury et al., 2012; Sarker et al., 2016). Although some practices have changed over the past 15 years (e.g., breastfeeding and newborn care practices), women in Bangladesh still avoid many activities during childbirth and the postnatal period because of cultural beliefs and practices (Edhborg et al., 2015, Choudhury et al., 2012). For example, Darmstadt et al. (2006) found that women did not go outside at night or the afternoon, or in a storm; further, they were not allowed outside with their hair down, or with the end of their sari (traditional dress) touching the ground during the postnatal period, as it was believed that these activities make women vulnerable to evil spirits.

Research further showed that while some foods were restricted during the seclusion period, some mothers-in-law imposed the consumption of kalijira vorta (mashed black cumin seed) and green banana with rice for a long time after childbirth, thinking that this is essential to keeping the woman's stomach cool and initiating the production of breast milk (Choudhury \& Ahmed, 2011). Choudhury and Ahmed (2011) found that the most commonly eaten foods during the postnatal period were rice, mashed potato, tea, green banana, black cumin and poppy seeds. These foods were believed to keep the stomach cool and produce breast milk. Rural mothers, especially those who are not economically well-off, eat last in the household, eating what is left over. Thus, while a proper 
diet is crucial for successful childbirth, mothers were also often deprived of it because of lack of money (Choudhury \& Ahmed, 2011). Further, pregnant women were instructed by female relatives to eat moderately so that their baby would not grow too large and make childbirth difficult (Chowdhury et al., 2003; Darmstadt et al., 2006; Sarker et al., 2016).

Rural people think that other people are able to pose a threat to the newly birthed woman and baby, who are vulnerable to evil spirits (bhoot) and the evil eye (najar) (Darmstadt et al., 2006). Therefore, women stay inside the house to avoid evil spirits (Choudhury \& Ahmed, 2011; Choudhury et al., 2012; Darmstadt et al., 2006). It is believed that evil influences can be reduced by the careful regulation of visitors (Darmstadt et al., 2006). A small fire is kept outside the door of the room where mother and baby lived (Darmstadt et al., 2006) because it is believed that evil spirits are frightened by an iron sickle kept on the floor at the bed head or by a lamp burning through the night. Darmstadt et al. (2006) also said that a piece of iron and an item of leather were kept near to the bed, to defend from evil spirits.

The results suggest that the utilisation of early postnatal care needs to be addressed in the policy and programmes of the Government of Bangladesh. Appropriate interventions should be made from the grass-roots level, as women (particularly in rural areas) still lack access to quality healthcare during childbirth and the postnatal period. Additionally, to improve maternal and neonatal health, the government needs to focus on women's education and empowerment, as the two are intimately intertwined. While efforts to increase the rate of exclusive breastfeeding have been successful in Bangladesh, the importance of the early initiation of breastfeeding is yet to be effective. Further programmes and projects should be undertaken to promote the early initiation of breastfeeding because the benefits contribute to neonatal survival and brain development.

\section{Conclusion}

This literature review shows that women in Bangladesh followed many cultural practices during childbirth and postnatal period. In rural Bangladesh, postnatal care behaviour is mostly imposed by traditional cultural practices. Therefore, it is important to understand women's cultural practices around childbirth, and in particular to understand their experiences during the postnatal period.

\section{Acknowledgements}

The first author is thankful to her $\mathrm{PhD}$ research supervisors and the University of New England (UNE) for providing UNE Strategic Scholarship and UNE Stipend Scholarship.

\section{Conflicts of Interest}

The authors declare no conflict of interest regarding the publication of this paper. 


\section{References}

Afsana, K., \& Rashid, S. F. (2001). The Challenges of Meeting Rural Bangladeshi Women's Needs in Delivery Care. Reproductive Health Matters, 9, 79-89. https://doi.org/10.1016/S0968-8080(01)90094-1

Afsana, K., \& Rashid, S. F. (2009). Constructions of Birth in Bangladesh. In H. Selin \& P. K. Stone (Eds.), Childbirth across Cultures: Ideas and Practices of Pregnancy, Childbirth and the Postpartum (Vol. 5, pp. 123-136). Springer Science and Business Media. https://doi.org/10.1007/978-90-481-2599-9_11

Andrews, J. Y., \& Dalal, K. (2011). Umbilical Cord-Cutting Practices and Place of Delivery in Bangladesh. International Journal of Gynecology \& Obstetrics, 114, 43-46. https://doi.org/10.1016/j.ijgo.2011.01.025

Ara, S., Islam, M. M., Kamruzzaman, M., Elahi, M. T., ShahinurRahman, S. S., \& Hossain, M. S. (2013). Assessment of Social, Economic and Medical Determinant of Safe Motherhood in Dhaka City: A Cross-Sectional Study. American Journal of Life Sciences, 1, 93-97. https://doi.org/10.11648/j.ajls.20130103.13

Blum, L. S., Sharmin, T., \& Ronsmans, C. (2006). Attending Home vs. Clinic-Based Deliveries: Perspectives of Skilled Birth Attendants in Matlab, Bangladesh. Reproductive Health Matters, 14, 51-60. https://doi.org/10.1016/S0968-8080(06)27234-3

Choudhury, N., \& Ahmed, S. M. (2011). Maternal Care Practices among the Ultra Poor Households in Rural Bangladesh: A Qualitative Exploratory Study. BMC Pregnancy and Childbirth, 11, Article No. 15. https://doi.org/10.1186/1471-2393-11-15

Choudhury, N., Moran, A. C., Alam, M. A., Ahsan, K. Z., Rashid, S. F., \& Streatfield, P. K. (2012). Beliefs and Practices during Pregnancy and Childbirth in Urban slums of Dhaka, Bangladesh. BMC Public Health, 12, Article No. 791. https://doi.org/10.1186/1471-2458-12-791

Chowdhury, A. M. R., Mahbub, A., \& Chowdhury, A. S. (2003). Skilled Attendance at Delivery in Bangladesh: An Ethnographic Study. Research and Evaluation Division.

Coughlan, M., Cronin, P., \& Ryan, F. (2013). Doing a Literature Review in Nursing, Health and Social Care. Sage.

Darmstadt, G. L., Syed, U., Patel, Z., \& Kabir, N. (2006). Review of Domiciliary Newborn-Care Practices in Bangladesh. Journal of Health Population and Nutrition, 24, 380-393.

Edhborg, M., Nasreen, H. E., \& Kabir, Z. N. (2015). “I Can't Stop Worrying about Everything"-Experiences of Rural Bangladeshi Women during the First Postpartum Months. International Journal of Qualitative Studies on Health and Well-Being, 10, Article ID: 26226. https://doi.org/10.3402/qhw.v10.26226

Freire, M. H. d. S., Stelmak, A. P., Santos, E. K. A. d., \& Bittencourt, R. (2014). Kangaroo Method as a Basis for Humanized Care for the Neonate and Family: Integrative Review. Journal of Nursing, 8, 3461-3472.

Haider, R., Rasheed, S., Sanghvi, T. G., Hassan, N., Pachon, H., Islam, S., \& Jalal, C. S. (2010). Breastfeeding in Infancy: Identifying the Program-Relevant Issues in Bangladesh. International Breastfeeding Journal, 5, Article No. 21.

https://doi.org/10.1186/1746-4358-5-21

Islam, M. T., Islam, N., Yoshimura, Y., Nisha, M. K., \& Yasmin, N. (2015). Newborn Care Practices in Rural Bangladesh. Research and Reports in Neonatology, 5, 65-72. https://doi.org/10.2147/RRN.S87122

Khan, M. I., \& Islam, K. (2006). Home Delivery Practices in Rural Bangladesh: A Case of Passive Violence to the Women. Bangladesh e-Journal of Sociology, 3, 80-89.

Moran, A. C., Choudhury, N., Khan, N. U. Z., Karar, Z. A., Wahed, T., Rashid, S. F., \& 
Alam, M. A. (2009). Newborn Care Practices among Slum Dwellers in Dhaka, Bangladesh: A quantitative and Qualitative Exploratory Study. BMC Pregnancy and Childbirth, 9, Article No. 54. https://doi.org/10.1186/1471-2393-9-54

National Health and Medical Research Council (2009). NHMRC Levels of Evidence and Grades for Recommendations for Developers of Guidelines. https://www.nhmrc.gov.au/ files nhmrc/file/guidelines/developers/nhmrc levels grad es evidence 120423.pdf

National Institute of Population Research and Training (NIPORT) (2016). Bangladesh Demographic and Health Survey 2014. https://dhsprogram.com/pubs/pdf/FR311/FR311.pdf

Parkhurst, J. O., Rahman, S. A., \& Ssengooba, F. (2006). Overcoming Access Barriers for Facility-Based Delivery in Low-Income Settings: Insights from Bangladesh and Uganda. Journal of Health, Population and Nutrition, 24, 438-445.

Rahman, A., Moran, A., Pervin, J., Rahman, A., Rahman, M., Yeasmin, S. et al. (2011). Effectiveness of an Integrated Approach to Reduce Perinatal Mortality: Recent Experiences from Matlab, Bangladesh. BMC Public Health, 19, Article No. 914. https://doi.org/10.1186/1471-2458-11-914

Sarker, B. K., Rahman, M., Rahman, T., Hossain, J., Reichenbach, L., \& Mitra, D. K. (2016). Reasons for Preference of Home Delivery with Traditional Birth Attendants (TBAs) in Rural Bangladesh: A Qualitative Exploration. PLoS ONE, 11, Article ID: e0146161. https://doi.org/10.1371/journal.pone.0146161

Shakya, B. (2006). Cultural Practices during Postnatal Period in Tamang Community in Bhaktapur District of Nepal. Journal of Nepal Health Research Council, 4, 1-6.

Sines, E., Syed, U., Wall, S., \& Worley, H. (2007). Postnatal Care: A Critical Opportunity to Save Mothers and Newborns. Washington, DC USA.

http://www.prb.org/pdf07/snl pncbrieffinal.pdf

Sultana, A. (2010). Patriarchy and Women's Subordination: A Theoretical Analysis. The Arts Faculty Journal, 4, 1-18. https://doi.org/10.3329/afj.v4i0.12929

Sundaram, M. E., Ali, H., Mehra, S., Shamim, A. A., Ullah, B., Rashid, M. et al. (2016). Early Newborn Ritual Foods Correlate with Delayed Breastfeeding Initiation in Rural Bangladesh. International Breastfeeding Journal, 11, Article No. 31. https://doi.org/10.1186/s13006-016-0090-9

Tarafder, T., \& Sultan, P. (2014). Reproductive Health Beliefs and Their Consequences: A Case Study on Rural Indigenous Women in Bangladesh. Australasian Journal of Regional Studies, 20, 351-374.

Tasnim, S., Rahman, A., \& Shahabuddin, A. K. M. (2010). Access to Skilled Care at Home during Pregnancy and Childbirth: Dhaka, Bangladesh. International Quarterly of Community Health Education, 30, 81-87. https://doi.org/10.2190/IQ.30.1.g

Varghese, R. P. (2007). Monster-in-Law? The Effect of Co-Resident Mother-in-Law on the Welfare of Bangladeshi Daughters-in-Law. University of Chicago.

Walton, L. M., \& Schbley, B. (2013). Cultural Barriers to Maternal Health Care in Rural Bangladesh. Online Journal of Health Ethics, 9, 1-12. https://doi.org/10.18785/ojhe.0901.03

Whittemore, R., \& Knafl, K. (2005). The Integrative Review: Updated Methodology. Journal of Advanced Nursing, 52, 546-553. https://doi.org/10.1111/j.1365-2648.2005.03621.x

Winch, P. J. (2005). Local Understandings of Vulnerability and Protection during the Neonatal Period in Sylhet District, Bangladesh: A Qualitative Study. The Lancet, 366, 478-485. https://doi.org/10.1016/S0140-6736(05)66836-5 